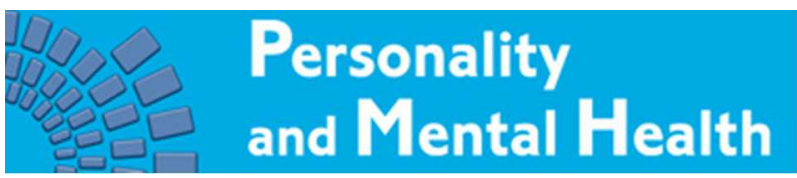

\title{
Implementation of Evidence-Based Treatments for Borderline Personality Disorder: The Impact of Organizational Changes on Treatment Outcome of Mentalization-Based Treatment
}

\begin{tabular}{|r|l|}
\hline Journal: & Personality and Mental Health \\
\hline Manuscript ID & Draft \\
\hline Wiley - Manuscript type: & Research Article \\
\hline Complete List of Authors: & $\begin{array}{l}\text { bales, dawn; MBT Nederland, MBT Netherlands; Psychotherapeutisch } \\
\text { Centrum De Viersprong, VISPD (Viersprong institute on studies of } \\
\text { personality disorders) } \\
\text { Timman, Reinier; Erasmus MC, Psychiatry - Medical Psychology and } \\
\text { Psychotherapy } \\
\text { Luyten, Patrick; Katholieke Universiteit Leuven } \\
\text { Busschbach, Jan; Erasmus Medical Centre, Department of Medical } \\
\text { Psychology and Psychotherapy; Viersprong Institute for Studies on } \\
\text { Personality Disorders , } \\
\text { Verheul, Roel; University of Amsterdam, Clinical Psychology; } \\
\text { Hutsebaut, Joost; Erasmus Medical Centre, Department of Medical } \\
\text { Psychology and Psychotherapy; Viersprong Institute for Studies on } \\
\text { Personality Disorders, }\end{array}$ \\
\hline Keywords: & $\begin{array}{l}\text { Mentalization-based treatment, implementation, quality maintenance, } \\
\text { adherence, psychotherapy }\end{array}$ \\
\hline \hline
\end{tabular}




\title{
Implementation of Evidence-Based Treatments for Borderline Personality Disorder: The Impact of Organizational Changes on Treatment Outcome of Mentalization-Based Treatment
}

\author{
Dawn L. Bales, Reinier Timman, Patrick Luyten, Jan Busschbach, Roel Verheul, \\ Joost Hutsebaut
}

Viersprong Institute for Studies on Personality Disorders (VISPD), the Netherlands

\author{
Author Note \\ Dawn L. Bales, Viersprong Institute for Studies on Personality Disorders (VISPD), MBT \\ Netherlands, The Netherlands; Reinier Timman, VISPD, The Netherlands; Patrick Luyten, VISPD, \\ University College London, United Kingdom; Jan Busschbach, VISPD, the Netherlands; Roel \\ Verheul, Center of Psychotherapy the Viersprong, The Netherlands; Joost Hutsebaut, VISPD, MBT \\ Netherlands, The Netherlands. \\ Reinier Timman and Jan Busschbach are also at Section of Medical Psychology and \\ Psychotherapy, Erasmus Medical Center Rotterdam, Rotterdam, the Netherlands. Patrick Luyten is \\ also at Faculty of Psychology and Educational Sciences, University of Leuven, Belgium. \\ Acknowledgements: The authors thank all participants in this study and the staff of the MBT \\ department in Bergen op Zoom, The Netherlands. In particular, they thank Maaike Smits (VISPD) for \\ her work coordinating data collection and processing the data, Odette Brand for her comments on this \\ paper, and Clare Farrar for copyediting the manuscript. \\ Correspondence concerning this article should be addressed to Dawn L. Bales, MBT \\ Netherlands, Postbus 7, 4660 AA Halsteren, The Netherlands. \\ E-mail: dawn.bales@mbtnederland.nl.
}


Implementation of Evidence-Based Treatment Programs: Impact of Organizational Changes on Treatment Outcome

\begin{abstract}
The quality of implementation of evidence-based treatment programs for borderline personality disorder (BPD) is a neglected issue. This paper aimed to explore the impact of organizational changes on treatment effectiveness of mentalization-based treatment (MBTDH). Consecutively referred BPD patients were divided into a pre-reorganization cohort (PRE-REORG) and a cohort during reorganization (REORG). Psychiatric symptoms (BSI) and personality functioning (SIPP-118) were compared at 18- and 36-month follow-up using multilevel modeling. Effect sizes in the PRE-REORG cohort were twice as large at 18 months (PRE-REORG: range 0.81-1.22; REORG: range 0.03-0.71) and three times as large at 36 months (PRE-REORG: range 0.81-1.80; REORG: range 0.27-0.81). Results suggest that even when MBT is successfully implemented, major organizational changes may have a considerable impact on its effectiveness. Specifically, the organizational changes were negatively related to adherence to the treatment model at organizational, team, and therapist level, which in turn was associated with a decrease in treatment effectiveness. The implications of these findings for the implementation of effective treatments for BPD in routine clinical practice are discussed.

Keywords: Mentalization-based treatment, implementation, quality maintenance, adherence, psychotherapy, treatment effectiveness, treatment outcome, borderline personality disorder.
\end{abstract}




\section{Implementation of Evidence-Based Treatments for Borderline Personality Disorder: The Impact of Organizational Changes on Treatment Outcome of Mentalization-Based Treatment}

Borderline personality disorder (BPD) is a serious and complex disorder that is characterized by high levels of emotional instability, impulsivity, and difficulties in interpersonal and social functioning (Bateman \& Fonagy, 2004), which cause severe impairments in occupational, interpersonal, and social functioning. Patients with BPD almost invariably have high psychiatric comorbidity, seriously impaired quality of life (Soeteman, Verheul, \& Busschbach, 2008), and a high economic burden of disease (Soeteman, Hakkaartvan Roijen, Verheul, \& Busschbach, 2008). Psychotherapy is considered to be the treatment of choice for BPD patients (Soeteman, Verheul, et al., 2008); (Leichsenring, Leibing, Kruse, New, \& Leweke, 2011). There is evidence supporting the efficacy of several types of psychotherapy for BPD; these are dialectical behavior therapy, schema-focused therapy, transference-focused psychotherapy, and mentalization-based treatment (MBT) (Leichsenring, et al., 2011).

Despite the evidence of the efficacy of these treatments, their implementation in routine clinical practice has been slow. A study in the Netherlands, for instance, estimated that only $23 \%$ of patients diagnosed with BPD received psychotherapy (Hermens, van Splunteren, van den Bosch, \& Verheul, 2011); a much smaller percentage received an evidence-based treatment. Little is known about the implementation of evidence-based treatments for BPD in other countries, but it is assumed that only a small minority of patients receive such interventions (Hermens, et al., 2011).

With growing interest in the implementation of evidence-based treatments for these patients has come realization of the importance of the quality of implementation (J. Hutsebaut, 
Bales, Busschbach, \& Verheul, 2012). The evidence in support of evidence-based treatments has typically been obtained under controlled (optimal) conditions in the context of randomized controlled trials, including extensive training and supervision of therapists, adherence monitoring, above-average organizational support, and involving therapists who typically show high levels of intrinsic motivation and competency. It remains unclear to what degree treatment outcome can be maintained under the suboptimal conditions that are often typical of routine clinical practice, particularly given the widespread budget cuts in mental health care. Various studies have shown that the dissemination of evidence-based treatments, away from the developers' lab, may result in a drop in outcome (Durlak \& DuPre, 2008; Henggeler, 2004; Schoenwald, 2008). This has been shown, for example, for multisystemic therapy for antisocial youth (Henggeler, 2004). In the field of personality disorders, the U.K. National Institute for Health and Clinical Excellence guidelines (2009) emphasize that unlike pharmacological treatments - where prescribers are assured of the quality of the product by manufacturers - the quality of a psychological intervention depends on therapists having the necessary skills and organizational support to replicate the intervention that has been found to be effective in research settings. This aligns with expert opinions that the outcome of psychotherapy may be highly dependent on the organizational context in which the treatment program is delivered (Bateman \& Krawitz, 2013). As an example of therapist factors, Davidson and colleagues (Davidson et al., 2006) found that competent therapists were able to avert more than five times as many suicidal acts as their less competent colleagues who had had the same training and supervision and used the same methods.

Elsewhere, we have argued that the implementation of multidisciplinary, team-based treatment programs, such as MBT for patients with BPD, is a complex process with several risks in relation to treatment safety and efficacy (J. Hutsebaut, et al., 2012). This conclusion was based on a study of the implementation of MBT for adolescents with BPD, which showed 
Implementation of Evidence-Based Treatment Programs: Impact of Organizational Changes on Treatment Outcome

that successful implementation of MBT was dependent on the successful management of several interacting factors at three interrelated levels: that of the organization, the team, and the individual therapist. More specifically, lack of support and implementation planning at the organizational level was associated with and further increased resistance to changes to the treatment program, as well as being associated with communication problems and lack of an adequate supervisory structure at the team level, and with a lack of competence and adherence to MTB at the therapist level.

Two recent studies of the implementation of DBT and SFT, two other evidence-based treatment programs for BPD (Nadort et al., 2009; van den Bosch \& Sinnaeve, 2015), similarly pointed to the importance of organizational factors, such as managers' commitment to the implementation of the program, the need for the program to be well embedded in the organization, and the importance of factors related to the team and individual therapists, such as team cohesion, commitment of therapists/team to the intervention, supervision, and consultation.

This paper seeks to further explore the importance of the quality of implementation of evidence-based treatments for BPD by addressing the influence of a major organizational change on the efficacy of MBT. It can be argued that even when a treatment program has been successfully implemented in a given setting, it is uncertain whether the same quality of treatment delivery can be maintained in the long term. Organizations and teams are dynamic entities. Teams might experience a high turnover of personnel, particularly in the context of treating patients with BPD; organizations change; team leaders, managers, and experts can change jobs; new team members may experience difficulties in being accepted in the team; and so on. It is questionable whether the effectiveness of a treatment program will be resistant to all these changes and dynamics. The issue of maintenance of treatment results in a 
Implementation of Evidence-Based Treatment Programs: Impact of Organizational Changes on Treatment Outcome

changing team and organizational environment has not yet been the subject of scientific study in the field of personality disorders.

The authors' own treatment setting underwent considerable organizational changes 4 years after the successful implementation of MBT, offering a unique opportunity to explore the impact of such changes on the treatment outcome of MBT. The National Institute for Personality Disorders at the Viersprong in The Netherlands has offered a day-hospital MBT program (MBT-DH) since 2004. In a naturalistic outcome study (D. Bales et al., 2012), we showed that MBT-DH was associated with similar outcomes to those reported in previous trials of MBT. However, after the publication of these findings, the treatment setting encountered significant organizational changes in a relatively short period of time (August 2008 to March 2010). First, the adult MBT unit expanded and a national MBT training program was started. Second, the implementation of a new adolescent MBT program was problematic (J. Hutsebaut, et al., 2012), resulting in high staff turnover, temporary curtailment of the program, high level of patient and parent dissatisfaction, safety risks for patients and staff, and negative publicity. Third, the management structure changed and the adult MBT unit had to merge with the newly developed adolescent MBT unit. These changes were accompanied by a tripling of personnel, many of whom were inexperienced in the MBT model. Fourth, during this period the unit's supervisor and trainers were partially deployed elsewhere. Finally, the former manager of the adult unit, an MBT expert (who had implemented MBT at the institution previously) changed jobs, and a clinician who, although experienced with other treatment modalities, had virtually no knowledge of MBT, was appointed to manage the newly merged MBT unit for adults and adolescents.

This study had two aims. First, we aimed to investigate the impact of major organizational changes on treatment effectiveness by comparing treatment outcomes before and during the reorganization. Second, we aimed to explore to what extent possible changes 
Implementation of Evidence-Based Treatment Programs: Impact of Organizational Changes on Treatment Outcome

in outcome could be accounted for by the impact of the reorganization on adherence at organizational, team, and therapist level by comparing both cohorts on a list of critical success factors for implementing MBT.

\section{Methods}

\section{Participants and Procedures}

Study participants were consecutively referred patients to the adult MBT unit of the National Institute for Personality Disorders at the Viersprong, The Netherlands. Major organizational changes took place at the institute between August 2008 and March 2010. For the purposes of this study, September 1, 2008 was taken as the cut-off point to separate the pre-reorganization cohort (PRE-REORG) from the cohort of patients who were treated during the reorganization (REORG). PRE-REORG patients had had at least 9 months of treatment before the organizational changes were implemented, that is, they started MBT-DH between August 2004 and December 2007. REORG patients had at least 9 months of treatment during the reorganization period, that is, they started day hospital MBT between September 2008 and April 2011.

As part of the standard intake procedure, patients underwent a detailed diagnostic screening including the Structural Clinical Interview for DSM disorders (SCID-II; Ekselius, Lindstrom, von Knorring, Bodlund, \& Kullgren, 1994; Weertman, Arntz, \& Kerkhofs, 2008), or the Structured Interview for DSM-IV Personality (SIDP-IV; Pfohl, Blum, \& Zimmerman, 1997). Patients meeting DSM-IV diagnostic criteria for BPD were included in the study. Exclusion criteria were kept to a minimum, and were (a) the presence of schizophrenia based on the SCID-I, (b) intellectual impairment (IQ <80) as assessed with the Wechsler Adult Intelligence Scale-III, (c) organic brain disorder, and (d) living further than 1 hour's travelling distance from the unit. The PRE-REORG cohort consisted of 41 patients. Due to logistical 
Implementation of Evidence-Based Treatment Programs: Impact of Organizational Changes on Treatment Outcome

reasons, four patients were not interviewed and had no formal BPD diagnosis. The SCID-II interview could not be completed for seven patients because they were too distressed at the time of the interview (e.g., heavy withdrawal symptoms, dissociative states, psychotic symptoms). As a result, 30 of the referred patients were included in the analyses. The REORG cohort consisted of 16 patients, who enrolled in the program between September 2008 and April 2011.

\section{Treatment}

In both cohorts, the MBT condition consisted of a maximum of 18 months of manualized MBT-DH (D. L. Bales \& Bateman, 2012; Bateman \& Fonagy, 2004, 2006), followed by a maximum of 18 months of maintenance mentalizing (group) therapy. This study reports on the treatment outcome of the day hospital phase (18 months) and of the mentalizing-maintenance therapy (after 36 months) for both cohorts.

The day hospital program includes implicit mentalizing groups (comprising daily group psychotherapy and weekly individual psychotherapy, and individual crisis planning from a mentalizing perspective) and explicit mentalizing groups (art therapy twice a week, mentalizing cognitive group therapy, and writing therapy). The weekly program ends with a social hour and community meeting (D. L. Bales \& Bateman, 2012; Bateman, Bales, \& Hutsebaut, 2013; Bateman \& Fonagy, 2004). Patients could also consult a team psychiatrist for medication upon request.

Treatment goals of MBT are: (1) to engage the patient in treatment, (2) to reduce psychiatric symptoms, (3) to improve social and interpersonal functioning, (4) to decrease the number of self-destructive acts and suicide attempts, and (5) to stimulate adequate care consumption and to prevent reliance on hospital admissions and prolonged inpatient care (Bateman \& Fonagy, 2006). To achieve these goals, all program components specifically 
Implementation of Evidence-Based Treatment Programs: Impact of Organizational Changes on Treatment Outcome

focus on enhancement of the patient's mentalizing capacity, that is, the mental process of understanding the self and others in terms of mental states such as thoughts, desires, intentions, and feelings. The theoretical assumption is that enhancing mentalizing improves the symptoms and functioning of patients with BPD (Bateman \& Fonagy, 2004).

\section{Outcome Measures}

This study focused on two key targets of MBT: improvements in (a) psychiatric symptoms and (b) personality functioning, assessed at the start of treatment and at $6,12,18$, 24, 30, and 36 months after the start of treatment. Assessments in both cohorts were conducted by independent research assistants.

\section{Psychiatric symptoms}

General psychiatric symptom distress was measured with the Brief Symptom Inventory (BSI; De Beurs \& Zitman, 2006; Derogatis \& Melisaratos, 1983), a well-validated questionnaire derived from the Symptom Checklist 90-Revised (SCL-90-R; Arrindell \& Ettema, 2003; Derogatis, 1977). In this study, we used the Global Severity Index (GSI), that is, the mean score of the 53 items of the BSI (range 0-4). Higher scores indicate more symptoms. De Beurs and Zitman (2006) reported a Cronbach's alpha of 0.96 for this instrument.

\section{Personality}

Personality functioning was measured using the 118-item Severity Indices of Personality Problems (SIPP-118; Verheul et al., 2008). The SIPP-118 measures 16 facets of (mal)adaptive personality functioning, which fit into five higher-order domains-Self-control, Identity Integration, Responsibility, Relational capacities, and Social Concordance-with lower scores reflecting more maladaptive levels of personality functioning. The SIPP has good psychometric properties and (cross-national) validity (Arnevik, Wilberg, Monsen, 
Implementation of Evidence-Based Treatment Programs: Impact of Organizational Changes on Treatment Outcome

Andrea, \& Karterud, 2009; Verheul, et al., 2008). Cronbach's alphas of between 0.69 and 0.84 have been reported for the facets.

\section{Statistical Analysis}

Differences in baseline characteristics between the two cohorts were analyzed by using chi-square tests for dichotomous variables and Student's $t$-tests for continuous variables. Multilevel modeling was used to evaluate changes in symptoms and personality functioning in both cohorts. Multilevel models make optimal use of incomplete repeated measures data with unbalanced time points (Little \& Rubin, 1987). Time was modeled in months before or after the start of the treatment. In a first step, saturated models were tested with intercept and slope (time) as random variables. For within-group analyses, time was defined as level 1 and patients as level 2. Time, quadratic time, and logarithm of time were entered as fixed effects. For between-group analyses, we added group and interactions between group and time to the fixed effects. The covariance structure was based on the deviance statistic using restricted maximum likelihood (Verbeke \& Molenberghs, 1997). Then, in a step-by-step procedure, fixed time effects that were not significant $(p>.10)$ were excluded from the model until a parsimonious final model was reached that did not differ significantly from the saturated model. Statistical significance was determined with the deviance statistic using ordinary maximum likelihood (Singer \& Willett, 2003). When removing nonsignificant effects, we decided that interaction effects should be nested under their respective main effects (Hox, 2002). Cohen's $d$ effect sizes (Cohen, 1992) were calculated using the estimated pooled standard deviations from the models. All analyses were based on the intention-to-treat principle. Patients who ended treatment prematurely were also followed and included in the outcome analyses. Statistical analyses were performed using SPSS version 20.0. 
Implementation of Evidence-Based Treatment Programs: Impact of Organizational Changes on Treatment Outcome

\section{Qualitative Study: The Quality of Implementation}

For the qualitative study, a focus group was organized to explore the impact of the institutional reorganization on adherence at organizational, team, and therapist level. Participants in the focus group were selected on the basis of their ability to assess adherence at two or more levels from several relevant perspectives; they consisted of two managers, three therapists who had been involved in treating patients from both cohorts, and two researchers who had been involved in research on MBT in the unit but were not involved in any of the treatments. Participants were blind to potential differences in treatment outcome between both cohorts. In a first round, participants individually assessed the quality of implementation of MBT-DH for both cohorts, based on a checklist measuring critical success factors of the implementation of MBT, which was derived from the quality manual of MBT (Bateman, et al., 2013) augmented with results from previous relevant implementation studies (Bateman, et al., 2013; J. Hutsebaut, et al., 2012). Second, a focus group discussion was led by the first author, in which a summary of the participants' ratings was presented, after which participants were invited to discuss the summary. Finally, the participants provided a consensus score for adherence to MBT in each of the cohorts on a 5-point Likert scale (ranging from very poor to very good).

\section{Results}

\section{Baseline characteristics}

As Table 1 shows, there were no significant baseline differences between the two cohorts. 


\section{Quality of implementation}

--- Table 2 about here ---

Table 2 presents the results of the consensus scores derived from the checklist and discussion in the focus group of adherence at organizational, team, and therapist level for the two cohorts. PRE-REORG scores were a mean 6.1 (range 4-7), suggesting very good adherence at organizational, team, and therapist level. During organizational changes (i.e., REORG), the mean adherence was scored at 2.4 (range 1-4), indicating poor adherence. The focus group ratings for adherence to each of the factors in both cohorts suggests that adherence at each level was better before the reorganization than during the reorganization.

\section{Between-group differences}

The estimates of the parameters in the final parsimonious mixed models are presented in Table 3. For the purpose of interpretation, the estimates at the start of treatment, 18 months and 36 months, as well as the pooled standard deviations and effect sizes derived from the models, are presented in Table 4 and depicted in Figure 1. Effect sizes on various outcomes in the PRE-REORG cohort were twice as large at 18 months (PRE-REORG: range .81-1.22, median 1.09; REORG: range .03-.71, median .53) and more than three times as large at 36 months (PRE-REORG: range .81-1.80, median 1.60; REORG: range .27-.81, median .48). The observed differences between the two cohorts were statistically significant at both 18 and 36 months for most outcome parameters (self-control, identity integration, responsibility, relational capacities, and social concordance). On the GSI we observed a trend toward statistical significance $(p<.07)$. 


\section{Discussion}

This study investigated the impact of major organizational changes on the treatment outcome of MBT-DH in a specialized MBT unit. Results indicated a serious reduction in the effectiveness of the same intervention during and after the major organizational changes. In fact, outcomes decreased by almost half in the REORG cohort. Consistent with our assumptions, results from individual ratings and the focus group showed considerable problems in the REORG cohort with regard to adherence to the treatment model at organizational, team, and therapist level. The results can be considered a first step toward understanding important barriers and facilitators in the implementation and maintenance of effective treatment programs in the field of personality disorders.

The current study shows that treatment outcomes in a treatment center may be subject to major fluctuations over time, and suggests that these fluctuations can at least in part be accounted for by the degree of adherence to the treatment model at the organizational, team, and therapist level. This is, to our knowledge, the first study in the field of personality disorders to highlight the difficulty of maintaining treatment outcome within a changing organizational context. It is important to emphasize that this study took place in a mental health care center involving therapists who were properly trained and supervised in the treatment model. Even during and after the organizational changes the structure of the program remained unchanged and there is suggestive (unpublished) evidence to believe that the level of adherence to the model was comparable to benchmark MBT programs across various countries. Under this assumption our study compared optimal MBT (typically showing large effect sizes) to suboptimal MBT (typically showing medium effect sizes). 
Implementation of Evidence-Based Treatment Programs: Impact of Organizational Changes on Treatment Outcome

If replicated, these findings may have important implications for the dissemination and implementation of evidence-based treatments such as MBT in the treatment of BPD.

Although initial pessimism regarding the treatment of BPD has been replaced by optimism (Stoffers et al., 2012), the results of this study emphasize the critical role of continuously ensuring adherence to the model at multiple levels. This study suggests that psychotherapy might be especially beneficial when delivered in organizations that are fully committed to the patient population and the treatment program, provide sufficient resources for implementing the program, and are capable of dealing with major reorganizations affecting the delivery of the program. Furthermore, psychotherapy might be especially effective when delivered by well-functioning teams with a clear demarcation of responsibilities, clear leadership, and commitment to an open and reflective team culture. Finally, psychotherapy might be optimally effective only when delivered by competent, well-trained therapists, who receive ongoing supervision and are committed to the treatment model.

This study has several strengths and limitations, and the results need to be interpreted taking these strengths and limitations into account. A strength is the importance and timeliness of the topic, which fits well with a growing recognition of the critical role of implementation science in health services research (Bammer, 2005; Berwick, 2006). It is a naturalistic study capturing real-life variables in a mental health setting that impact quality of care. Limitations include the relatively small sample sizes in each cohort. This limitation is somewhat mitigated by the fact that the observed differences in outcome between the two cohorts were large. A second limitation is that the distinction between the cohorts (i.e., the choice of a cut-off date separating the two) was made retrospectively. This concern is somewhat mitigated by the fact that the division of cohorts was based on relatively objective grounds (i.e., major organizational changes), but further controlled research is necessary to replicate these findings. Third, with regard to the qualitative study, some participants were not 
Implementation of Evidence-Based Treatment Programs: Impact of Organizational Changes on Treatment Outcome

completely unfamiliar with our hypotheses concerning the importance of implementation issues, as one of our previous papers on this topic (Joost Hutsebaut et al., 2011) had been shared among members of the unit, which might have influenced ratings during the focus discussion. However, all participants in the focus group were unaware of our finding that outcomes during the reorganization indicated a marked drop in treatment effectiveness; they were merely asked to rate the impact of the changes in the organization on adherence to the MBT model at organizational, team, and therapist level. Finally, the study design did not allow us to investigate whether organizational, team, or therapist factors, or a combination of these factors, were responsible for the observed decrease in outcomes.

Despite these limitations, this study suggests the importance of organizational conditions influencing treatment outcome in the treatment of BPD. Organizations will always be dynamic entities. Besides inevitable changes that occur within organizations, broader reorganizations of health care systems are also likely to impact treatment adherence on different levels. The finding that such changes may have a negative impact on treatment outcome are alarming and highlight the need to develop strategies to optimize organizational, team, and therapist functioning in order to maintain and maximize the quality of psychotherapy for BPD patients in changing organizational contexts. We therefore urgently need more studies on the necessary conditions for the implementation and maintenance of effective treatment programs. Furthermore, we need to develop strategies to guarantee, monitor, and adjust conditions under which these treatments remain effective. Only then can we justify the claim that psychotherapy can be an effective treatment for BPD. 
Implementation of Evidence-Based Treatment Programs: Impact of Organizational Changes on Treatment Outcome

\section{References}

Arnevik, E., Wilberg, T., Monsen, J. T., Andrea, H., \& Karterud, S. (2009). A cross-national validity study of the Severity Indices of Personality Problems (SIPP-118). Personality and Mental Health, 3(1), 41-55. doi: 10.1002/pmh.60

Arrindell, W. A., \& Ettema, J. H. M. (2003). SCL-90 - Herziene handleiding bij een multidimensionele psychopathologie-indicator. Lisse, The Netherlands: Swets Publishers.

Bales, D., van Beek, N., Smits, M., Willemsen, S., Busschbach, J. J., Verheul, R., \& Andrea, H. (2012). Treatment outcome of 18-month, day hospital mentalization-based treatment (MBT) in patients with severe borderline personality disorder in the Netherlands. Journal of Personality Disorders, 26(4), 568-582. doi: 10.1521/pedi.2012.26.4.568

Bales, D. L., \& Bateman, A. W. (2012). Partial hospitalization settings. In A. W. Bateman \& P. Fonagy (Eds.), Handbook of mentalizing in mental health practice (pp. 197-227). Washington, DC: American Psychiatric Publishing.

Bammer, G.(2005). Integration and implementation Sciences: building a new specialization. Ecology and Society, 10:6.

Bateman, A. W., Bales, D. L., \& Hutsebaut, J. (2013). A quality manual for MBT. London, UK: Anna Freud Centre.

Bateman, A. W., \& Fonagy, P. (2004). Psychotherapy for borderline personality disorder: Mentalization-based treatment. Oxford, UK: Oxford University Press.

Bateman, A. W., \& Fonagy, P. (2006). Mentalization-based treatment for borderline personality disorder: A practical guide. Oxford, UK: Oxford University Press. 
Implementation of Evidence-Based Treatment Programs: Impact of Organizational Changes on Treatment Outcome

Bateman, A. W., \& Krawitz, R. (2013). Borderline personality disorder: An evidence-based guide for generalist mental health professionals. Oxford, UK: Oxford University Press.

Berwick, D.M. (2003). Disseminating innovations in health care. Journal American Medical Association, 289, 1969-1975.

Cohen, J. (1992). A power primer. Psychological Bulletin, 112(1), 155-159.

Davidson, K., Norrie, J., Tyrer, P., Gumley, A., Tata, P., Murray, H., \& Palmer, S. (2006). The effectiveness of cognitive behavior therapy for borderline personality disorder: Results from the borderline personality disorder study of cognitive therapy (BOSCOT) trial. Journal of Personality Disorders, 20(5), 450-465. doi:

10.1521/pedi.2006.20.5.450

De Beurs, E., \& Zitman, F. (2006). The Brief Symptom Inventory (BSI): Betrouwbaarheid en validiteit van een handzaam alternatief voor de SCL-90. Maandblad Geestelijke Volksgezondheid, 61(2), 120-141.

Derogatis, L. R. (1977). SCL-90: Administartion, scoring and procedures manual-I for the R(evised) version. Baltimore, MD: John Hopkins University School of Medicine, Clinical Psychometrics Research Unit.

Derogatis, L. R., \& Melisaratos, N. (1983). The Brief Symptom Inventory: An introductory report. Psychological Medicine, 13(3), 595-605.

Durlak, J. A., \& DuPre, E. P. (2008). Implementation Matters: A Review of Research on the Influence of Implementation on Program Outcomes and the Factors Affecting Implementation. American Journal of Community Psychology, 41(3-4), 327-350. doi: 10.1007/s10464-008-9165-0

Ekselius, L., Lindstrom, E., von Knorring, L., Bodlund, O., \& Kullgren, G. (1994). SCID II interviews and the SCID Screen questionnaire as diagnostic tools for personality 
Implementation of Evidence-Based Treatment Programs: Impact of Organizational Changes on Treatment Outcome

disorders in DSM-III-R. Acta Psychiatrica Scandinavica, 90(2), 120-123. doi: 10.1111/j.1600-0447.1994.tb01566.x

Henggeler, S. W. (2004). Decreasing effect sizes for effectiveness studies- implications for the transport of evidence-based treatments: Comment on Curtis, Ronan, and Borduin (2004). Journal of Family Psychology, 18(3), 420-423. doi: 10.1037/0893-

3200.18.3.420

Hermens, M. L., van Splunteren, P. T., van den Bosch, A., \& Verheul, R. (2011). Barriers to implementing the clinical guideline on borderline personality disorder in the Netherlands. Psychiatric Services, 62(11), 1381-1383. doi:

10.1176/ps.62.11.pss6211_1381

Hox, J. (2002). Multilevel analysis: Techniques and applications. Mahwah, NJ: Lawrence Erlbaum Associates.

Hutsebaut, J., Bales, D., Kavelaars, M., Gerwen, J., Busschbach, J., \& Verheul, R. (2011). Implementatie van een behandelmodel voor persoonlijkheidsgestoorde adolescenten. [journal article]. Tijdschrift voor Psychotherapie, 37(3), 162-176. doi: 10.1007/s12485-011-0030-5

Hutsebaut, J., Bales, D. L., Busschbach, J. J., \& Verheul, R. (2012). The implementation of mentalization-based treatment for adolescents: A case study from an organizational, team and therapist perspective. [Article]. International Journal of Mental Health Systems, 6(1), 10. doi: 10.1186/1752-4458-6-10

Leichsenring, F., Leibing, E., Kruse, J., New, A. S., \& Leweke, F. (2011). Borderline personality disorder. [Review]. Lancet, 377(9759), 74-84. doi: 10.1016/S01406736(10)61422-5

Little, R. J. A., \& Rubin, D. B. (1987). Statistical analysis with missing data. New York, NY: John Wiley and Sons. 
Implementation of Evidence-Based Treatment Programs: Impact of Organizational Changes on Treatment Outcome

Nadort, M., Arntz, A., Smit, J. H., Giesen-Bloo, J., Eikelenboom, M., Spinhoven, P., . . van Dyck, R. (2009). Implementation of outpatient schema therapy for borderline personality disorder with versus without crisis support by the therapist outside office hours: A randomized trial. Behaviour Research and Therapy, 47(11), 961-973. doi: 10.1016/j.brat.2009.07.013

National Institute for Health and Clinical Excellence. (2009). Borderline personality disorder: Treatment and management. Clinical Guideline 78. In B. P. Society (Ed.), (Vol. 78). Leicester, UK: National Collaborating Centre for Mental Health.

Pfohl, B., Blum, N., \& Zimmerman, M. (1997). Structured interview for DSM-IV personality (SIDP-IV). Washington, DC: American Psychiatric Press.

Schoenwald, S. K. (2008). Toward Evidence-Based Transport of Evidence-Based Treatments: MST as an Example. Journal of Child \& Adolescent Substance Abuse, 17(3), 69-91. doi: 10.1080/15470650802071671

Singer, J. D., \& Willett, J. B. (2003). Applied longitudinal data analysis: Modeling change and event occurrence. Oxford, UK: Oxford University Press.

Soeteman, D. I., Hakkaart-van Roijen, L., Verheul, R., \& Busschbach, J. J. (2008). The economic burden of personality disorders in mental health care. Journal of Clinical Psychiatry, 69(2), 259-265.

Soeteman, D. I., Verheul, R., \& Busschbach, J. J. (2008). The burden of disease in personality disorders: diagnosis-specific quality of life. Journal of Personality Disorders, 22(3), 259-268. doi: 10.1521/pedi.2008.22.3.259

Stoffers, J. M., Vollm, B. A., Rucker, G., Timmer, A., Huband, N., \& Lieb, K. (2012). Psychological therapies for people with borderline personality disorder. Cochrane Database of Systematic Reviews, 8(8), CD005652. doi: 10.1002/14651858.CD005652.pub2 
Implementation of Evidence-Based Treatment Programs: Impact of Organizational Changes on Treatment Outcome

van den Bosch, L. M. C., \& Sinnaeve, R. (2015). Dialectische gedragstherapie in Nederland: Implementatie en consolidatie. Tijdschrift voor Psychiatrie, 57(Oktober), 719-726.

Verbeke, G., \& Molenberghs, G. (Eds.). (1997). Linear mixed models in practice: A SAS oriented approach (Vol. 126). New York, NY: Springer.

Verheul, R., Andrea, H., Berghout, C. C., Dolan, C., Busschbach, J. J., van der Kroft, P. J., . . . Fonagy, P. (2008). Severity Indices of Personality Problems (SIPP-118):

Development, factor structure, reliability, and validity. Psychological Assessment, 20(1), 23-34. doi: 10.1037/1040-3590.20.1.23

Weertman, A., Arntz, A., \& Kerkhofs, M. (2008). SCID II: Gestructureerd klinisch interview voor het vaststellen van DSM-IV stoornissen. Amsterdam, The Netherlands: Harcourt Test Publishers. 


\section{Figure 1}

Estimated courses of outcome variables
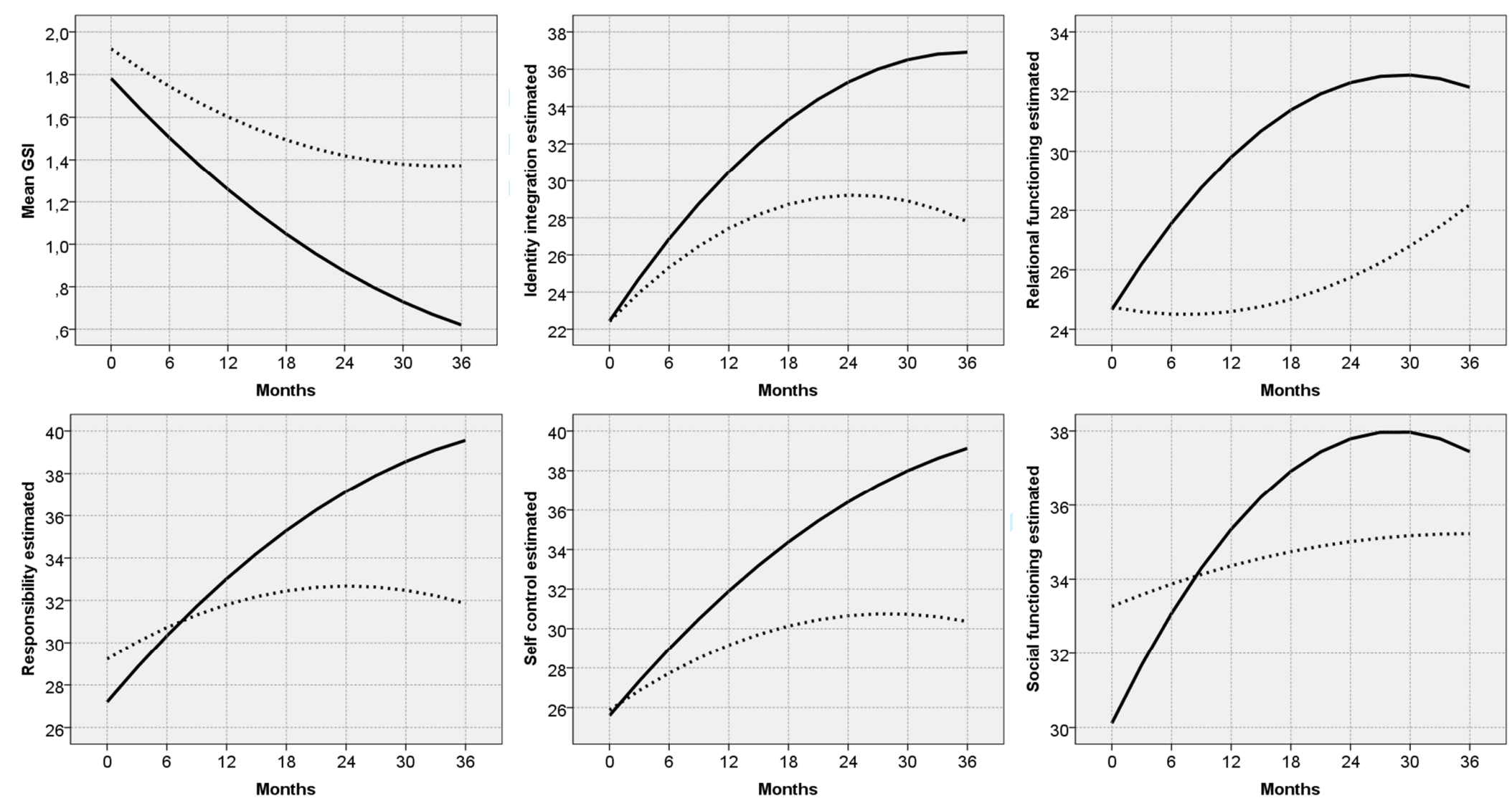

Note: Solid lines = 'Pre-reorganization Cohort' $($ PRE-REORG); dotted lines = During reorganization Cohort' $($ REORG) 
Table 1

Baseline characteristics of Pre-reorganization (PRE-REORG) and During reorganization Cohorts (REORG)

\begin{tabular}{|c|c|c|c|c|}
\hline & $\begin{array}{l}\quad \text { 'Pre- } \\
\text { reorganization } \\
\text { Cohort' (PRE- } \\
\text { REORG) } \\
\quad \mathrm{n}=30\end{array}$ & $\begin{array}{c}\text { 'During } \\
\text { reorganization } \\
\text { Cohort' (REORG) } \\
n=16\end{array}$ & & \\
\hline & $\mathrm{n}(\%)$ & n $(\%)$ & $\chi^{2}$ & $p$ \\
\hline Female & $21(70 \%)$ & $13(81 \%)$ & 0.23 & 0.64 \\
\hline $\begin{array}{l}\text { Education } \\
\text { - lower } \\
\text { - high school } \\
\text { - higher }\end{array}$ & $\begin{array}{r}4(13 \%) \\
24(80 \%) \\
2(7 \%)\end{array}$ & $\begin{array}{r}2(13 \%) \\
12(75 \%) \\
2(13 \%)\end{array}$ & 0.45 & 0.80 \\
\hline Married & $3(10 \%)$ & $2(13 \%)$ & 0.00 & 1.00 \\
\hline $\begin{array}{l}\text { Living with: } \\
\text {-Partner } \\
\text {-Parent } \\
\text {-Children }\end{array}$ & $\begin{array}{l}7(23 \%) \\
6(20 \%) \\
4(13 \%)\end{array}$ & $\begin{array}{l}3(19 \%) \\
5(31 \%) \\
3(19 \%)\end{array}$ & $\begin{array}{l}0.00 \\
0.24 \\
0.03\end{array}$ & $\begin{array}{l}1.00 \\
0.63 \\
0.96\end{array}$ \\
\hline Paid work / study & Mean (sd) & $\begin{array}{l}4(25 \%) \\
\text { Mean }(\mathrm{sd})\end{array}$ & 0.08 & 0.77 \\
\hline Age & $29.8(6.3)$ & $27.9(5.7)$ & -1.02 & 0.31 \\
\hline GSI & $1.79(0.70)$ & $1.86(0.61)$ & 0.34 & 0.74 \\
\hline SIPP: & & & & \\
\hline Self-control & $25.0(6.5)$ & $25.9(6.8)$ & 0.44 & 0.66 \\
\hline Identity integration & $23.0(7.0)$ & $21.9(7.1)$ & -0.50 & 0.62 \\
\hline Responsibility & $26.9(6.0)$ & $29.8(7.3)$ & 1.46 & 0.15 \\
\hline Relational functioning & $24.6(6.5)$ & $24.9(7.5)$ & 0.17 & 0.87 \\
\hline Social concordance & $29.8(6.9)$ & $33.9(6.7)$ & 1.91 & 0.06 \\
\hline Number of BPD traits & $6.9(1.5)$ & $6.3(1.2)$ & -1.59 & 0.12 \\
\hline
\end{tabular}


Table 2

Consensus ratings on adherence of two cohorts at organizational, team and therapist level

\begin{tabular}{|c|c|c|}
\hline Organization & $\begin{array}{l}\text { Cohort } 1 \\
\text { (PRE- } \\
\text { REORG) }\end{array}$ & $\begin{array}{c}\text { Cohort } 2 \\
\text { (REORG) }\end{array}$ \\
\hline $\begin{array}{l}\text { Commitment and support within the organization to fully } \\
\text { implement MBT }\end{array}$ & 7 & 4 \\
\hline Availability of comprehensive implementation plan & 6 & $2 / 3$ \\
\hline Sound financial management & 7 & 4 \\
\hline Continuity in management & 7 & $2 / 3$ \\
\hline $\begin{array}{l}\text { Organization of MBT unit (clear structure, defined roles and } \\
\text { responsibilities, etc.) }\end{array}$ & 6 & 2 \\
\hline Stability in the organization & 5 & 3 \\
\hline $\begin{array}{l}\text { Staff selection based on competences regarding treating BPD } \\
\text { patients, MBT competence, team composition, affinity with } \\
\text { treatment model }\end{array}$ & 7 & 1 \\
\hline \multicolumn{3}{|l|}{ Team } \\
\hline Well balanced team composition & 6 & $2 / 3$ \\
\hline Team size $(8-12)$ & 6 & 1 \\
\hline Leadership (clear leadership as supported by the whole team) & 6 & 3 \\
\hline Team cohesion: secure, open, cohesive team & 7 & 2 \\
\hline $\begin{array}{l}\text { Mentalizing environment: open, responsive, mentalizing } \\
\text { atmosphere }\end{array}$ & 6 & $2 / 3$ \\
\hline Availability of MBT expertise at the unit & $6 / 7$ & $2 / 3$ \\
\hline MBT training and supervision & $5 / 6$ & $2 / 3$ \\
\hline $\begin{array}{l}\text { Consistency: ability of the team to deliver treatment in consistent } \\
\text { manner }\end{array}$ & 6 & $2 / 3$ \\
\hline $\begin{array}{l}\text { Coherency: team utilizes theoretically coherent (MBT) } \\
\text { framework to tailor interventions }\end{array}$ & 6 & $2 / 3$ \\
\hline Continuity & 6 & 2 \\
\hline $\begin{array}{l}\text { Structure: Program structure, clear definition of roles and } \\
\text { responsibilities }\end{array}$ & 6 & 2 \\
\hline \multicolumn{3}{|l|}{ Therapist } \\
\hline MBT experience with the model & 4 & 2 \\
\hline $\begin{array}{l}\text { Adherence to the model: adherence and competence with the } \\
\text { model in individual sessions and group sessions }\end{array}$ & 6 & $2 / 3$ \\
\hline Commitment among all team members to MBT-model & 7 & 3 \\
\hline
\end{tabular}

$1=$ very poor; $2=$ poor; $3=$ acceptable $; 4=$ Adequate $5=$ Good; $6=$ Very good $7=$ excellent 


\section{Table 3}

Effect estimates and standard errors of final between group mixed models.

\begin{tabular}{|c|c|c|c|c|c|c|}
\hline $\begin{array}{l}\text { Estimate [standard error] } \\
\text { p-value }\end{array}$ & Intercept & Time linear & Time quadratic & $\begin{array}{c}\text { 'Pre- } \\
\text { reorganization } \\
\text { Cohort' (PRE) }\end{array}$ & $\begin{array}{l}\text { 'Pre- } \\
\text { reorganization } \\
\text { Cohort' (PRE) } \\
\text { * Time linear }\end{array}$ & $\begin{array}{c}\text { 'Pre- } \\
\text { reorganization } \\
\text { Cohort' (PRE) } \\
\text { * Time quadratic }\end{array}$ \\
\hline GSI psychiatric symptoms & $\begin{array}{l}1.92[0.19] \\
<0.001\end{array}$ & $\begin{array}{c}-0.032[0.011] \\
0.006\end{array}$ & $\begin{array}{c}0.0005[0.0003] \\
0.094\end{array}$ & $\begin{array}{c}-0.14[0.23] \\
0.553\end{array}$ & $\begin{array}{c}-0.017[0.009] \\
0.071\end{array}$ & \\
\hline SIPP self-control & $\begin{array}{l}25.9[1.6] \\
<0.001\end{array}$ & $\begin{array}{c}0.35[0.13] \\
0.007\end{array}$ & $\begin{array}{c}-0.006[0.003] \\
0.058\end{array}$ & $\begin{array}{c}-0.28[1.94] \\
0.887\end{array}$ & $\begin{array}{c}0.25[0.09] \\
0.008\end{array}$ & \\
\hline SIPP identity integration & $\begin{array}{l}22.4[2.1] \\
<0.001\end{array}$ & $\begin{array}{l}0.55[0.14] \\
\quad<0.001\end{array}$ & $\begin{array}{c}-0.011[0.004] \\
0.004\end{array}$ & $\begin{array}{c}0.014[2.47] \\
0.995\end{array}$ & $\begin{array}{l}0.25[0.09] \\
0.005\end{array}$ & \\
\hline SIPP responsibility & $\begin{array}{l}29.2[1.60] \\
\quad<0.001\end{array}$ & $\begin{array}{l}0.29[0.10] \\
0.006\end{array}$ & $\begin{array}{c}-0.006[0.003] \\
0.034\end{array}$ & $\begin{array}{c}-2.02[1.93] \\
0.299\end{array}$ & $\begin{array}{l}0.27[0.06] \\
\quad<0.001\end{array}$ & \\
\hline SIPP Relational capacities & $\begin{array}{l}24.7[1.79] \\
\quad<0.001\end{array}$ & $\begin{array}{l}-0.07[0.18] \\
0.705\end{array}$ & $\begin{array}{c}0.005[0.005] \\
0.390\end{array}$ & $\begin{array}{c}-0.08[2.21] \\
0.969\end{array}$ & $\begin{array}{l}0.61[0.22] \\
0.006\end{array}$ & $\begin{array}{c}-0.014[0.006] \\
0.031\end{array}$ \\
\hline SIPP social concordance & $\begin{array}{l}33.3[1.68] \\
\quad<0.001\end{array}$ & $\begin{array}{c}0.11[0.13] \\
0.386\end{array}$ & $\begin{array}{c}-0.002[0.004] \\
0.676\end{array}$ & $\begin{array}{r}-3.16[2.07] \\
0.132\end{array}$ & $\begin{array}{l}0.44[0.15] \\
0.004\end{array}$ & $\begin{array}{c}-0.008[0.004] \\
0.065\end{array}$ \\
\hline
\end{tabular}


Table 4

Estimates and effect sizes for both cohorts

\begin{tabular}{|c|c|c|c|c|c|c|}
\hline \multirow[t]{2}{*}{ Outcome } & \multicolumn{2}{|c|}{\begin{tabular}{c}
\multicolumn{1}{c}{ 'Pre- } \\
reorganization \\
Cohort' (PRE- \\
REORG)
\end{tabular}} & \multicolumn{2}{|c|}{$\begin{array}{c}\text { 'During } \\
\text { reorganization } \\
\text { Cohort' } \\
\text { (REORG) }\end{array}$} & \multicolumn{2}{|c|}{ Difference } \\
\hline & Estimate & $\begin{array}{l}\text { Effect } \\
\text { size }\end{array}$ & Estimate & $\begin{array}{l}\text { Effect } \\
\text { size }\end{array}$ & $\begin{array}{c}(\mathrm{sd}) \\
\text { Effect } \\
\text { size }^{1}\end{array}$ & $p$ \\
\hline \multicolumn{7}{|c|}{ GSI Psychiatric symptoms } \\
\hline Start & 1.78 & & 1.92 & & $(0.79)$ & \\
\hline 18 months & 1.05 & -1.00 & 1.49 & -0.58 & -0.42 & 0.07 \\
\hline 36 months & 0.62 & -1.56 & 1.37 & -0.74 & -0.82 & 0.07 \\
\hline \multicolumn{7}{|c|}{ SIPP Self-control } \\
\hline Start & 25.6 & & 25.9 & & $(7.0)$ & \\
\hline 18 months & 34.4 & 1.22 & 30.1 & 0.59 & 0.63 & 0.008 \\
\hline 36 months & 39.1 & 1.76 & 30.4 & 0.58 & 1.17 & 0.008 \\
\hline \multicolumn{7}{|c|}{ SIPP Identity integration } \\
\hline Start & 22.4 & & 22.4 & & $(8.9)$ & \\
\hline 18 months & 33.3 & 1.22 & 28.7 & 0.71 & 0.51 & 0.005 \\
\hline 36 months & 36.9 & 1.63 & 27.8 & 0.60 & 1.03 & 0.005 \\
\hline \multicolumn{7}{|c|}{ SIPP Responsibility } \\
\hline Start & 27.2 & & 29.2 & & $(6.9)$ & \\
\hline 18 months & 35.3 & 1.18 & 32.5 & 0.47 & 0.71 & $<0.001$ \\
\hline 36 months & 39.6 & 1.80 & 31.9 & 0.38 & 1.42 & $<0.001$ \\
\hline \multicolumn{7}{|c|}{$\begin{array}{l}\text { SIPP Relational } \\
\text { capacities }\end{array}$} \\
\hline Start & 24.7 & & 24.7 & & (7.4) & \\
\hline 18 months & 31.4 & 0.91 & 25.0 & 0.04 & 0.88 & 0.002 \\
\hline 36 months & 32.1 & 1.02 & 28.2 & 0.47 & 0.55 & 0.117 \\
\hline \multicolumn{7}{|c|}{$\overline{S I P P}$ Social concordance } \\
\hline Start & 30.1 & & 33.3 & & $(6.7)$ & \\
\hline 18 months & 36.9 & 0.99 & 34.7 & 0.21 & 0.79 & 0.001 \\
\hline 36 months & 37.4 & 1.02 & 35.2 & 0.27 & 0.80 & 0.029 \\
\hline
\end{tabular}

